\title{
Adaptive Sliding Mode Control for Magnetic levitation system
}

\author{
Shibly Ahmed Al-Samarraie \\ Bashar Fateh Midhat \\ Rand Ahmed Bahaa Al-Deen \\ Control \& Systems Eng. Dep., University of Technology, Baghdad, IRAQ \\ 60132@uotechnology.edu.iq_60170@uotechnology.edu.iq cse.60270@uotechnology.edu.iq \\ Received: 21-Nov.-2017 Revised: 11-Dec.-2017 Accepted: 18-Jan.-2018 \\ http://doi.org/10.29194/NJES21020266
}

\begin{abstract}
:
In this paper, an Adaptive Sliding Mode Controller (ASMC) is designed and applied for a magnetic levitation system (Maglev) where a steel ball is desired to be stabilized at a desired position with existence of uncertainty in system model. Additionally, a sliding mode differentiator (SMD) is used for estimating the ball velocity since it's needed for the controller to work properly. The designed controller and differentiator are applied practically to an experimental laboratory size magnetic levitation system and the results were plotted to show the behavior of the system under the effect of the designed controller. The experimental results reveal clearly the effectiveness and ability of the suggested controller in forcing the steel ball to follow various desired position.
\end{abstract}

Keywords: Sliding mode differentiator, Adaptive sliding mode control, Magnetic levitation system.

\section{Introduction}

Magnetic levitation is a method which describe that an object is levitated in a controlled magnetic field with no support. The magnetic field has the opposite power to gravity attraction of the ball. Maglev features are efficient, frictionless, far-out sounding technologies[1].In Figure(1)the steel ball is levitated by virtue of the electromagnetic field against the gravity force. And control signal represents the voltage that altered into current via a driver included within the Maglev unit, where steel ball is take a position along the electromagnet perpendicular axis. And for the ball position is obtained by a set of infrared rays transmitters and receiver that were detected, the infrared ray is cut off by means of steel ball vertical movement [2].

Recently many researches have been done of controlling the Maglev system. In [3, 4], the feedback linearization method was proposed in order to obtain a controller design for Maglev system. The reason behind this easy dynamic model was for the nominal of parameters system that investigated at the procedure design, also it was noticed that parameters has variations due to conditions of environment or thermal drifts that resulted in some stability problems, a controller robustness and accuracy. Nonlinear controllers [5, $6]$, linear controllers and robust like $\mathrm{H} \infty$ and optimal control [7, 8], control based on phase space $[9,10,11]$ fuzzy control and methods of neural network [12] were other approaches that proposed for controlling Maglev systems. Generally, a suggested model dynamic for this system ordinarily own a kind of uncertainties because of simplified dynamic equation and its parameters. Furthermore, the measurements for position of the levitated object described as noisy that it drives to several hardness in the systems feedback control.

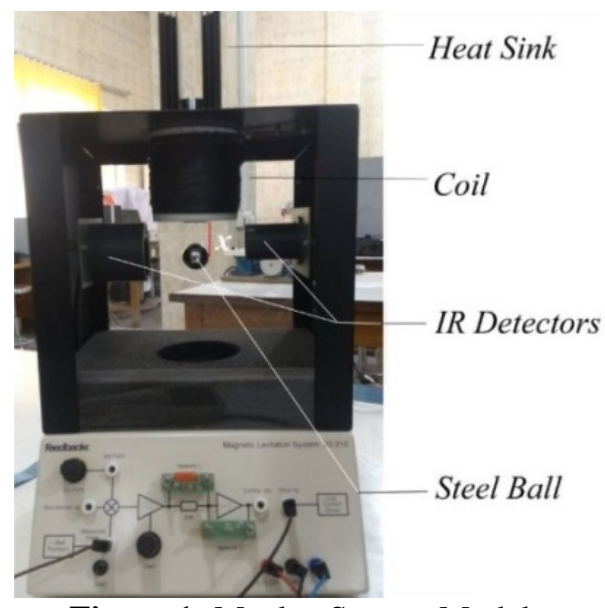

Figure 1: Maglev System Model.

The approach of sliding mode control is considered as the important and efficient tools to be designed under name of robust controllers and dynamical systems that are operating with parameter's uncertainty and output disturbance [13]. For the first implementation of ASMC on Maglev systems executed in [14]. It presented that an ASMC provides preferable transient and better response performance than classical sliding mode control (CSMC) controllers. But, the existing dynamics has been neglected in the model also the ball's movement was limited at range of 1 $\mathrm{mm}$. Chen et al. [15] designed an ASMC instead of many various type of Maglev systems which named dual-axis positioning for maglev system. Also Buckner [16] offered a steps to estimate the bounds of uncertainty utilizing artificial neural network, consequently implement it to SMC of a maglev system. New methodologies which proposes in [14] with designing the ASMC. The pinpoint is to get achievement for robust adaptive gain and control law of sliding mode adaptive 
with existence of uncertainties without knowing of its bound (but only the feature bounds known). The suggested ways consist of taking an adaptive control gain which confirms a sliding mode for finite time.

While some system states are unavailable, the differentiator will regenerate these states. Here which worked as an estimator is a controller to estimate the unknown system states of that depend on the measured outputs and inputs. It is fundamentally a numerical regeneration for system, came by the system input with signal presenting the difference between the system measured value and observer outputs [17]. The skillfulness to produce a sliding motion where the error difference of the output of the differentiator and output of measured plant guarantees a Sliding Mode Differentiator (SMD) that presents a set of estimated states which for sure accurately proportional to the actual plant output . As soon as differentiator referred to Luenberger, the distinction between an output of the plant and the differentiator fed back linearly into the differentiator. But, with the existence of disturbance and uncertainty, a Luenberger differentiator is usually (a) Incapable to impose the output of the estimation for error to be zero and (b) the status of differentiator do not converge to the system states [13].

This paper, consist an ASMC is proposed for the maglev system. It is designed in order to force a steel ball to tracking a desired position utilizing force of magnetic. Furthermore, a SMD is also designed for velocity estimation.

This research is organized as follows subordinate: in section two the mathematical model for the maglev system is represented. In section three and four, the ASMC is designed, and then in section five the SMD is designed. In section six the designed controllers are implemented practically to a real time maglev system and finally some conclusions are addressed in section seven.

\section{Description of Maglev Mathematical Model:}

The Maglev system shown in Figure (2) it consists of a magnetic suspension system, which aim to control the perpendicular ball position by means of increasing the electromagnet current through the input voltage signal. The nonlinear model of Maglev system is gathering between the current coil and the position of steel ball as in following:

The Maglev system nonlinear model is described as in Eq. (1) below:

$m \ddot{x}=m g-F_{C}$

where $F_{c}=k \frac{i^{2}}{x_{1}^{2}}, k$ is the coil constant, $m$ is the ball mass and $g$ the gravity while $F_{c}$ is the magnetic force produced by the coil. To offer the entire model there will be a relation between the coil current, $u$ the control signal that insert analyzing the hole Maglev circuit. However, an inner control loop is enforced Maglev to saving a current related with control voltage that generated:

$$
i=k_{1} \cdot u
$$

The bound of control voltage signal is set to[+5 $v$ to $-5 v]$. The steel ball is detected by an infrared sensor that can be featured the vertical direction of the steel ball from the horizontal ones. The distance for this ball from coil minimum and maximum are $0.5 \mathrm{~cm}$ and $0.25 \mathrm{~cm}$, respectively [16, 17]. The differential equations which describe the dynamics of Maglev system is specified by Eqs. (1 and 2).

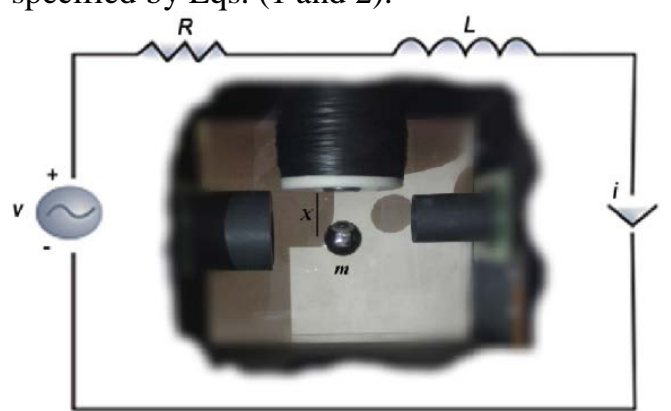

Figure 2: The Maglev steel ball Schematic.

\section{Design of Adaptive Sliding Mode Control:}

Any engineering system is assume adaptive if it can preserve its behavior, or be out despite of variations in its circumstances or in its own parameter. On the other hand, small variations or little ranges of variation in structure of this system or parameters of system may considered as uncertainty that treated with dynamic operation as via the design of statically process or by the design of feed-forward and control feedback systems [18].Now talking about the rules of ASMC, the first ASMC law used the concept of equivalent control that inters dynamics of low pass filter also parameter which was hard for making tuning [19].The second ASMC is completely original. The speculation of the perturbations not needed through control equivalent as in [20] (Theorem 2) also not overvalue the gain control which was as in [21] (Theorem 1). Moreover, the general second ASMC gain algorithm demand less effort of parameters tuning instead of the first one:

$$
u(s, t)=-k \cdot \operatorname{sign}(s(x, t))
$$

where the gain adaptation law is defined by

$\dot{k}=\left\{\begin{array}{ll}k(t) \cdot|s(x, t)| \cdot \operatorname{sign}(|s(x, t)|-\epsilon) & \text { if } k>\mu \\ \mu & \text { if } k \leq \mu\end{array}\right.$. 
In this adaptation law (4), $K(0)>0, \bar{K}>$ $0, \epsilon>0$ and $\mu>0$ very small and positive number. The parameter is inters only to get a positive values for $k$. In the complement, for argumentation and prove, assume that $k(t)>$ $\mu$ for all $t>0$ [14].

\section{Adaptive Sliding Mode Design For Maglev System :}

The purpose of ASMC is to force the states of Maglev system to access and remain on a particular sliding surface. Throughout sliding motion the ball position make tracking for the desired position by means of controlling the control voltage signal. It is common knowledge in SMC, the first step design is to choose the discontinuous surface to obtain the sliding motion that demonstrates the desired features. With regard to the discontinuous function usage, it's essential properties, the system closed loop robustness also the convergence in finite time [22]. To get rid of these difficulties, as for example, an approximate signum function able to be utilized or by adding a LPF with ASMC in order to reduce chattering [23].Considering the SMC control signal as;

$$
u= \begin{cases}V_{\max } & \text { if } s>0 \\ 0 & \text { if } s \leq 0\end{cases}
$$

Where $V_{\max }$ is the maximum used voltage. According to the suggested SMC law (5), a famous unwanted chattering behavior will be induced as a result of the discontinuity at switching surface $(s=0)$. In order to remove chattering, the SMC law (5) is replaced with an approximate continuous function given by;

$u=\frac{V_{\max }}{2}\left(1+\frac{2 * k}{\pi} * \tan ^{-1}(\alpha * s)\right)$

Here the design parameter $k(t)$ is determined according to the following[25]; set the initial value for a dummy variable $\mu$ as $\mu_{\text {initial }}=k$,then;

$$
\dot{\mu}=\rho *|s(x, t)| * \operatorname{sign}(|s(x, t)-\epsilon|) .
$$

Then $k(t)$ is chose to the next rules;

if $\left\{\begin{array}{ccc}K_{m n}<\mu<K_{m x} & \text { then } \quad k=\mu \\ \mu \leq K_{m n} & \text { then } \quad k=K_{m n} \\ \mu \geq K_{m x} & \text { then } \quad k=K_{m x}\end{array}\right.$

Where $k>0, \epsilon>0, K_{m n}<k(0)<K_{m x}, K_{m n}$ is the minimum possible value of $k(t)$ and $K_{m x}$ its maximum possible value. The SMC built in Simulink as an embedded function with saturation as shown in Fig. (3)\&(A-1) in Appendix (A):

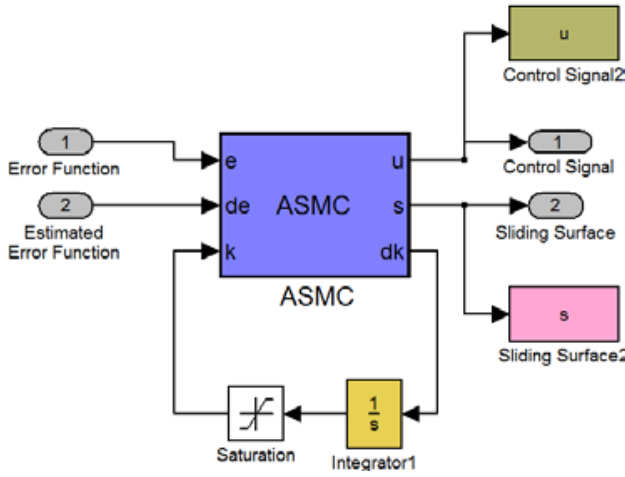

Figure 3: The Simulink of SMC as an embedded function.

\section{Design of Sliding Mode Differentiator:}

For here the section about sliding mode differentiator (SMD) constructing to mimic of ball position derivative i.e., the steel ball velocity $x_{2}$. The dynamics of differentiator utilized here is depending on the work presented in $[26,27]$. A classical SMD is given as the dynamical system;

$$
\left.\begin{array}{c}
\sigma=x_{1}-\tilde{x}_{1} \\
\dot{\tilde{x}}=\gamma\left(\frac{2}{\pi}\right) \tan ^{-1}(\alpha * \sigma) \\
\tau \dot{v}+v=\gamma\left(\frac{2}{\pi}\right) \tan ^{-1}(\alpha * \sigma)
\end{array}\right\}
$$

where $\tilde{x}_{1}$ is the estimation of $x_{1}$ such that $\tilde{x}_{1}(0)=x_{1}(0), \sigma$ is the error function, that offer the switching function of the SMD dynamics. Whereas, $\gamma, \alpha$ and $\tau$ are the parameters of differentiator that are chosen such that the error differentiation is get to a minimum. The SMD establish in Simulink as a system block as shown in Fig. (A-2) in Appendix (A), where $\gamma=40, k=$ $20, \tau=0.02 \mathrm{sec}$.

\section{Simulations Result and Discussions:}

The implementation of the proposed ASMC law (8) for practical work on the computercontrolled Maglev is examined. The configuration is presented in Fig. (1). The ASMC parameters that were used for the entire experiments are $\lambda=$ $1, V_{\max }=2 v, \alpha=2.5, \quad k_{\max }=4, k_{\min }=$ $1, \mu_{\text {initial }}=1.5, \epsilon=0.01, \rho=17$. The experiment results for different desired ball position are presented below.

In the results below the ball is first levitated manually in order to enter the electromagnetic field. Therefore the Maglev system was without ASMC controller, and as result a delay time was appeared as shown in the figures of the present work.

A. Experimental Results of ASMC for $x_{d}=$ 0.0125:

In this experimental work the desired position $x_{d}=0.0125 \mathrm{~m}$ was selected, under the proposed ASMC the ball settle down and reach 
the desired target as shows in Figure(4), while the sliding variable get reaches the sliding manifold which clarified in Figure(5). Finally, Figure(6) presents the plot of control voltage signal that reaches to less than one volt for controlling the ball position.

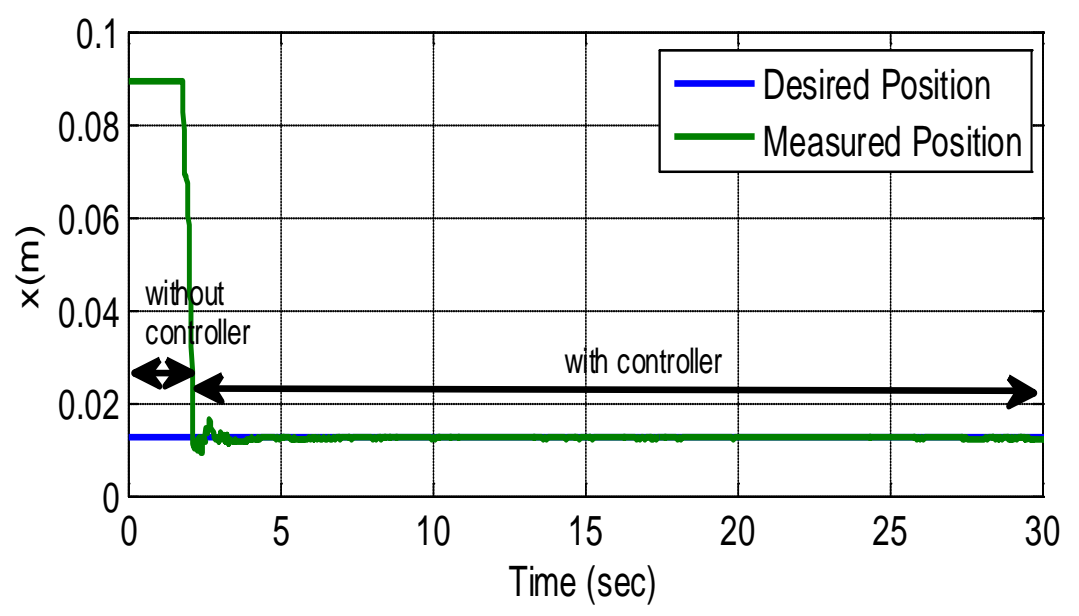

Figure 4: Plot of the measured position that tracks the reference $x_{d}=0.0125$.

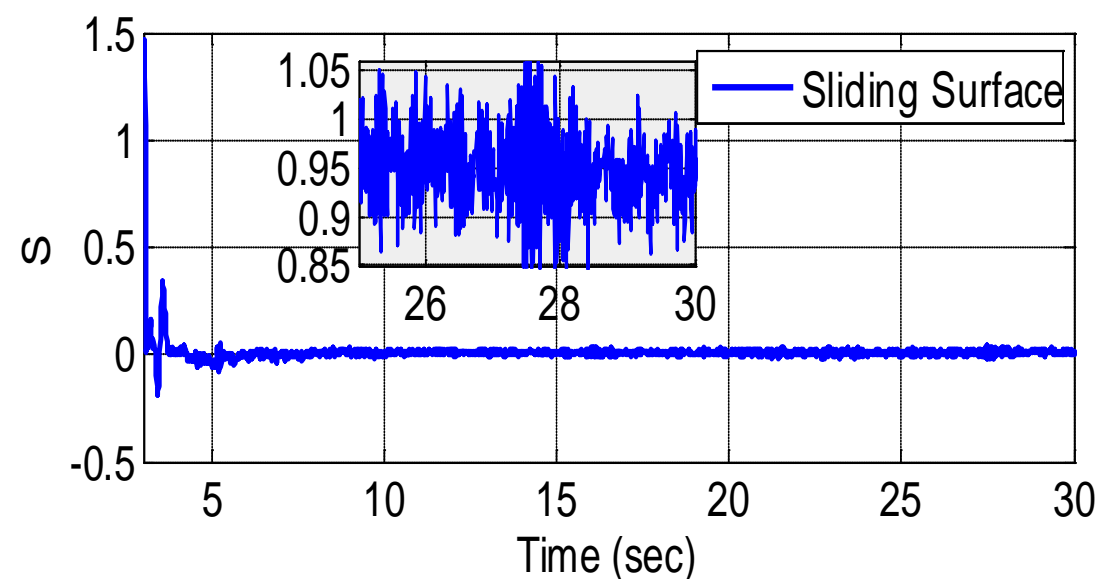

Figure 5: Sliding Surface $\left(x_{d}=0.0125\right)$.

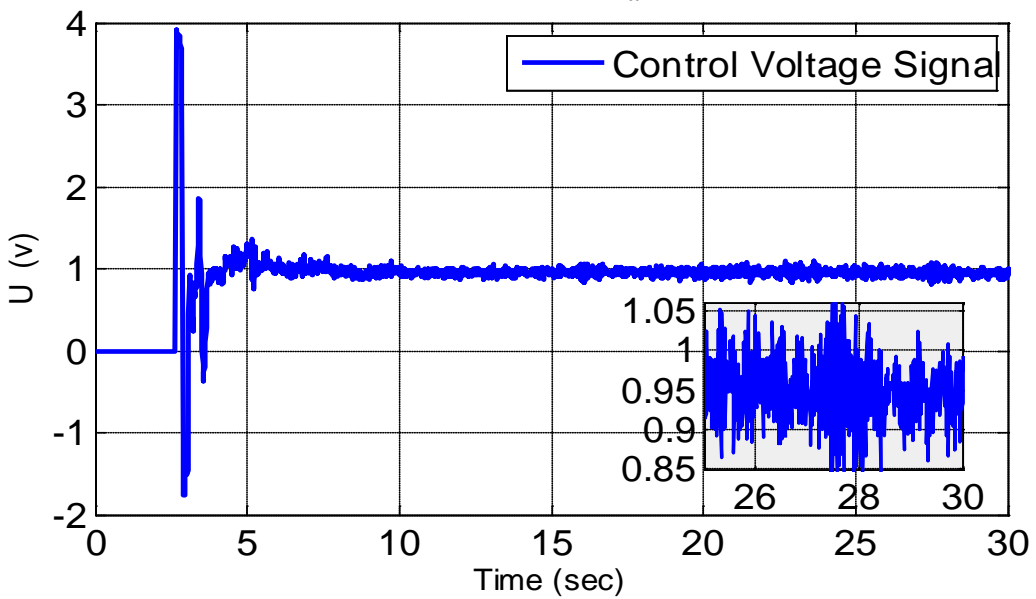

Figure 6 : Control Voltage Signal $\left(x_{d}=0.0125\right)$.

\section{B. Experimental Results of ASMC} for $x_{d}=0.0256$ :

The second experiment has taken another desired ball position which is $x_{d}=0.0256 \mathrm{~m}$. The proposed ASMC forces the ball reaches stability and obtains the desired position as shows in Fig. (7).
This is a direct result of forcing the sliding variable to the sliding manifold $s=0$ as clarified in Fig. (8). The control voltage signal is plotted in Fig. (9), where it can be seen that control effort needs approximately 1 volt in order to maintain the ball at $0.0256 \mathrm{~m}$. 


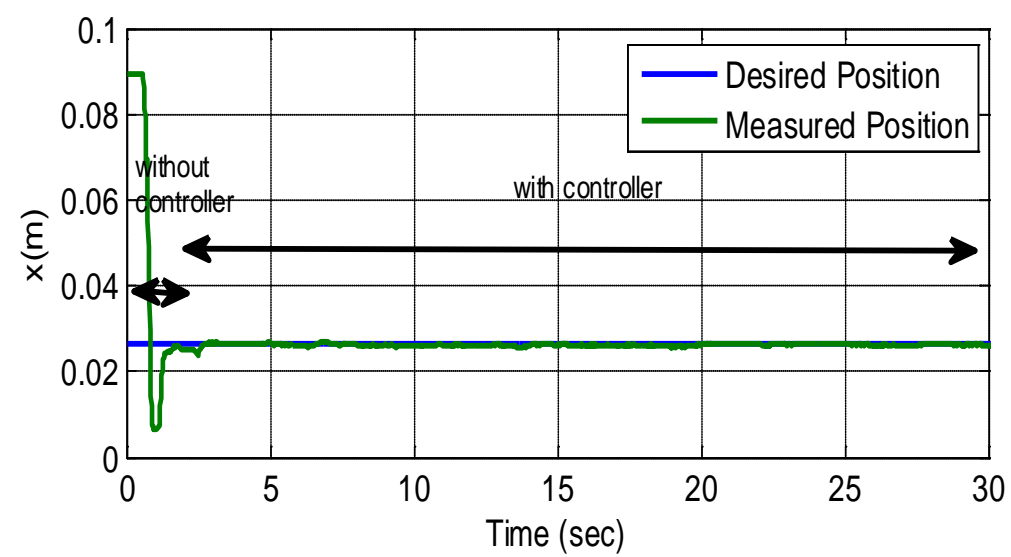

Figure 7 : Plot of the measured position that tracks the reference (at $\mathrm{x}=0.0265$ ).

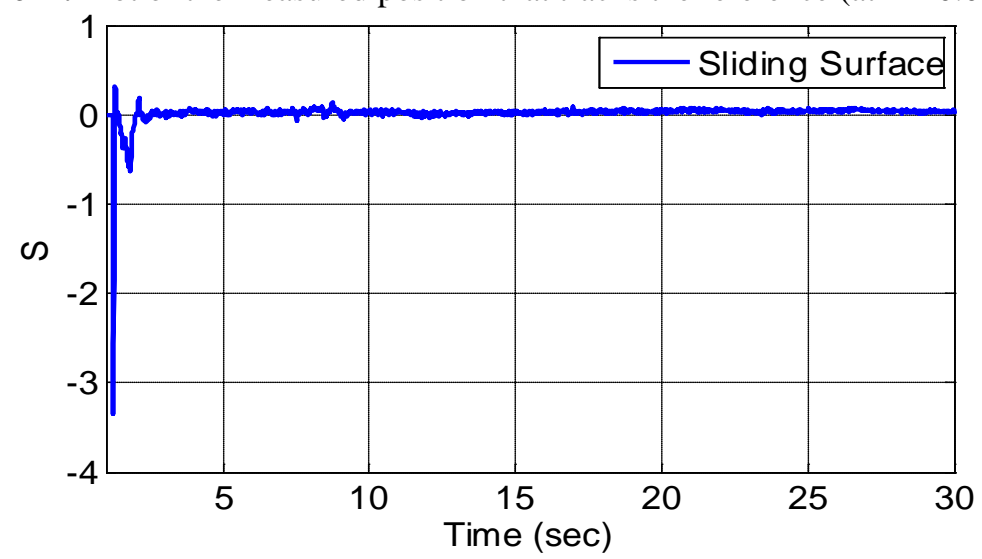

Figure 8: Sliding Surface (at $\mathrm{x}=0.0256$ ).

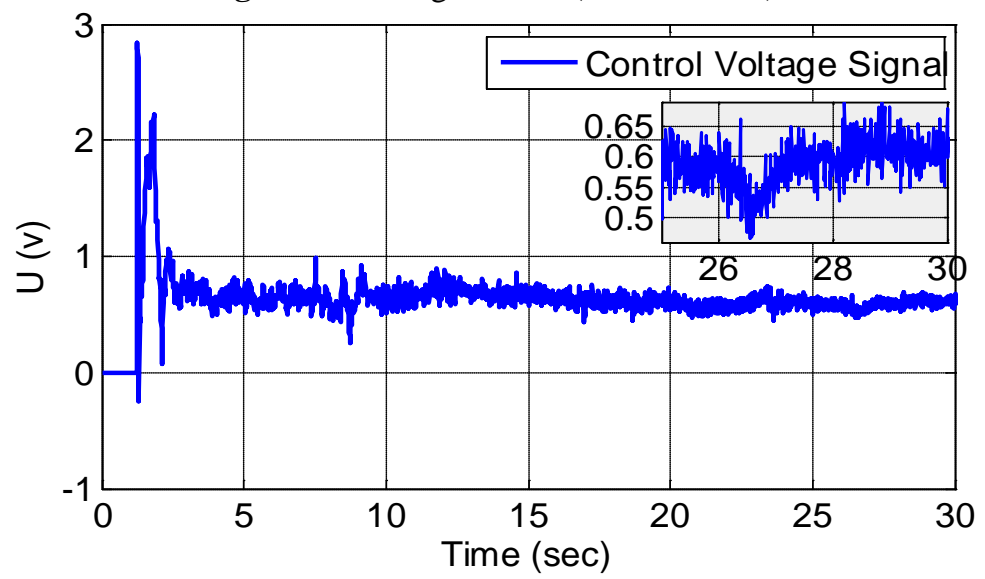

Figure 9: Control Voltage Signal (at $\mathrm{x}=0.0256)$.

C. Experimental Results of ASMC for sinusoidal desired ball position:

This experiment has taken the desired position as $x_{d}=0.03+0.007 * \sin (\pi t)$. The ball position for the selected desired ball position has been plotted with time in Figure(10). This plot showed the excellent performance for the proposed ASMC. This behavior can also be expressed from Figure(11) that the ASMC forces the sliding variable to get reaches the sliding manifold. The system dynamics is exchanged by $\dot{e}+e=0$ at the sliding manifold. As a result, the error difference of the measured and the desired goes to zero asymptotically and therefore a steel ball position tracking the desired path for sinusoidal input reference. Moreover, the control voltage signal has been plotted in Figure(12), with maximum voltage value is less than the chosen $V_{\text {max }}=2.1 v$. Finally, the estimated ball velocity via SMD, which used in the switching functions is shown in Figure(13). 


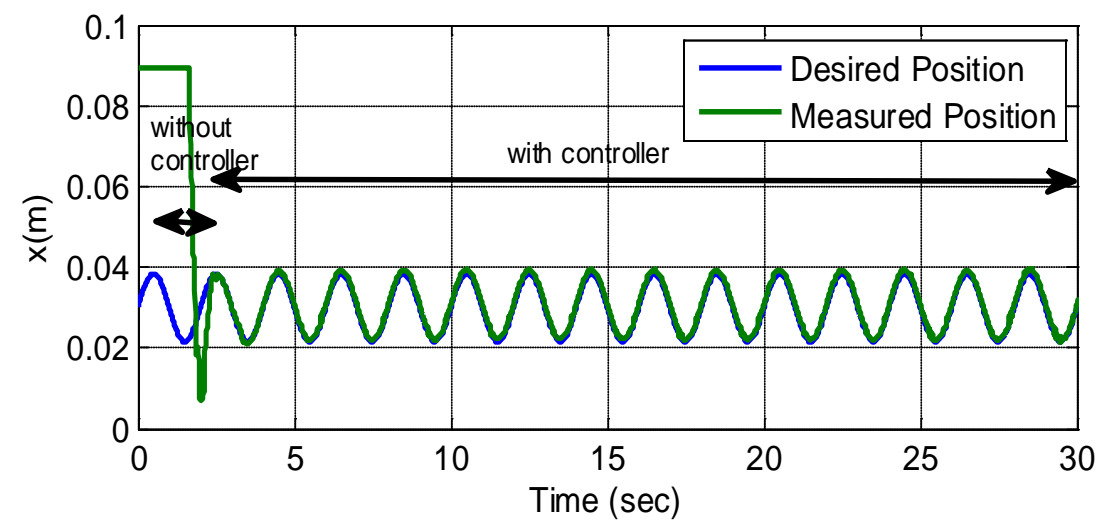

Figure 10: Plot the measured ball position (sinusoidal desired position tracking).

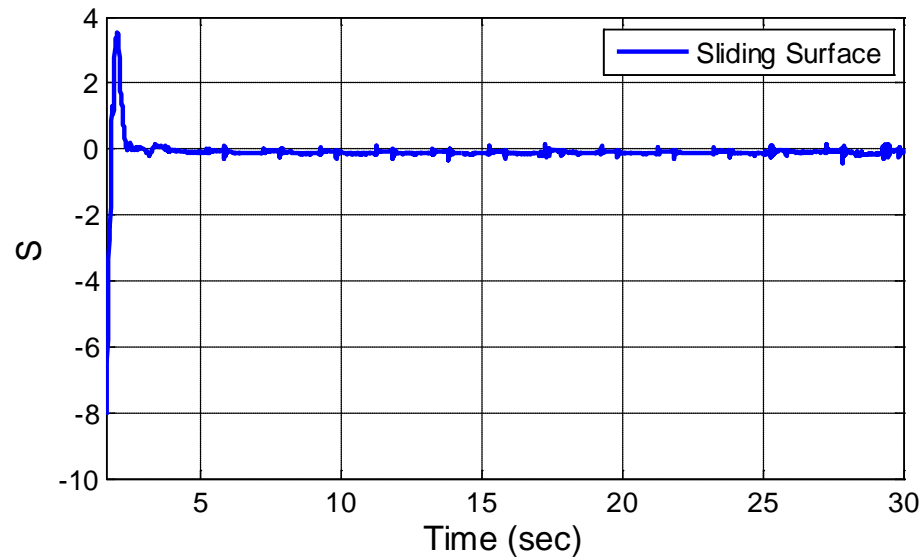

Figure 11: Sliding Surface (sinusoidal desired position tracking).

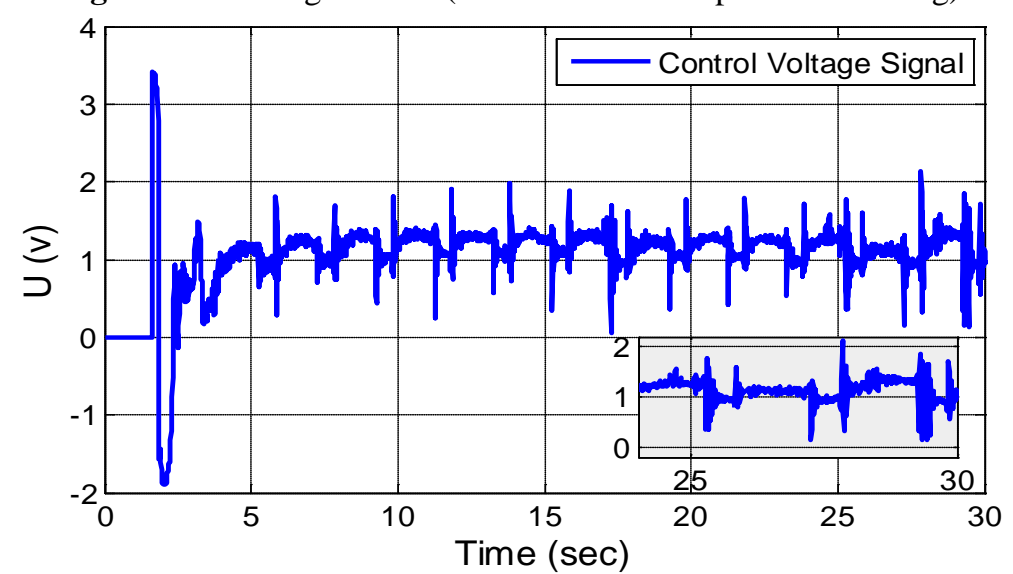

Figure 12: Control Voltage Signal (sinusoidal desired position tracking).

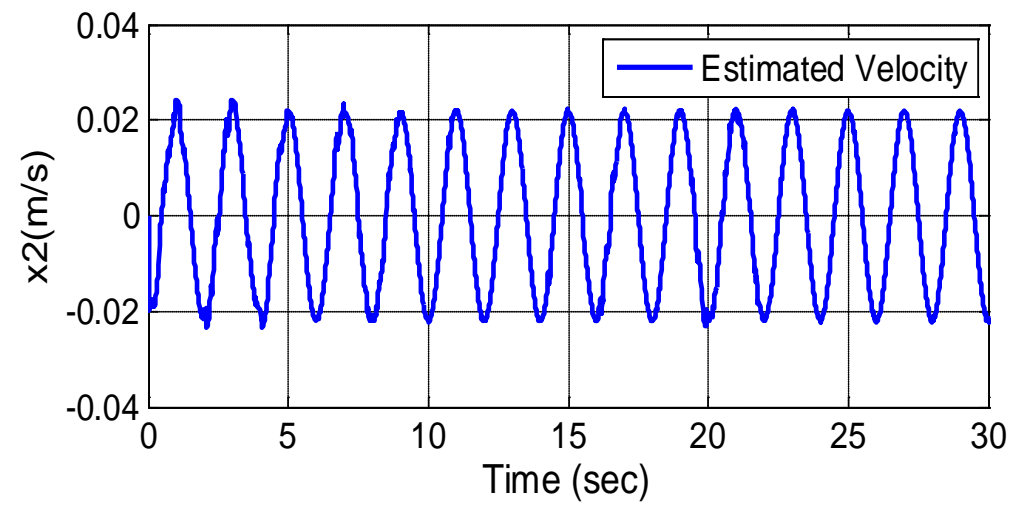

Figure 13: Estimated Velocity (sinusoidal desired position tracking). 


\section{Conclusions:}

The design of ASMC with SMD for the Maglev system is used in this research paper. The basic thing of the design is control the steel ball position for tracking the desired reference trajectory with existence of uncertainty in system model and the measurement of steel ball position only. The practical experimental results, with the desired ball position $0.0125 \mathrm{~m}, 0.0265 \mathrm{~m}$ also for sinusoidal input reference clarified the effectiveness of the proposed controller where one second was needed to make the ball reach the reference trajectory.

\section{References:}

[1] Rote , D. M., \&Cai , Y. "Review of Dynamic Stability of Repulsive-Force Maglev Suspension System”. IEEE Trans. Magn., Vol. 53, No. 2, 1383-1390, 2017.

[2] B. Naumović, M. and R. Veselić, B. (2008). "Magnetic Levitation System In Control Engineering Education”. Facta Universitatis, 7, No 1, pp. 151 - 160.

[3] Trumper, D. L., Olson, M., \&Subrahmanyan, P. K.,'Linearizing Control of Magnetic Suspension Systems”, IEEE Transactions on Control Systems Technology, Vol. 24, No. 2, pp. 427-438, 2017.

[4] Barie, W., \&Chiasson, J. "Linear and Nonlinear State-Space Controllers for Magnetic Levitation", International Journal of Systems Science, Vol.27, No. 1, pp. 1153-1163, 2017.

[5] Huang, C. M., Yen, J. Y., \& Chen, M.-S., "Adaptive Nonlinear Control of Repulsive Maglev Suspension Systems. Control Engineering Practice, Vol.8, No. 5, pp. 1357-1367, 2010.

[6] Yang , Z. J., \&Tateish, M. "Robust nonlinear control of a magnetic levitation system via back step-ping approach”. Proc. 37th SICE Annual Conference (SICE'98), Japan, pp.1063-1066, 2012.

[7] Fujita, M., Matsumura, F., \& Uchida, K."Experiments on the $\mathrm{H} \infty$ disturbance attenuation control of a magnetic suspension system”. Proc. 29th IEEE Conference on Decision and Control, Hawaii.pp.2773-2778, 2010.

[8] Fujita, M., Namerikawa, T., Matsumura, F., \& Uchida, K. " $\mu$-synthesis of an Electro-magnetic Suspension System”. IEEE Trans. Automatic Control, Vol. 40, No. 3, 530-536, 2015.

[9] Zhao, F., Loh, S. C., \& May, J. A. "PhaseSpace Nonlinear Control Toolbox: The Maglev Experience", $5^{\text {th }}$ International Hybrid Systems. Workshop (P. Antsaklis, W. Kohn, M. Lemmon, A. Nerode, and S. Sastry, eds.).Lecture Notes in Computer Science, 1567, pp. 429-444, 2009.

[10] Chen, C. H. "Nonlinear System Control Using Adaptive Neural Fuzzy Networks Based on a Modified Differential Evolution”. IEEE Trans on, Systems, MAN, and Cybernetics-Part C:
Applications and Reviews, Vol. 39, No. 4, 459473, 2009.

[11] Lin, F. J., Teng, L. T., \&Shieh, P. H. "Hybrid controller with recurrent neural network for magnetic levitation system”. IEEE Trans. Magn., Vol. 41, No. 7, pp. 2260-2269, 2015.

[12] Li, T. H. S., Kuo, C.L., \&Guo, N.R.”Design of an EP-Based Fuzzy Sliding Mode Control for a Magnetic Ball Suspension System”.International Journal of Systems, Vol. 33, No. 1, pp. 15231531, 2017.

[13] Spurgeon, Sarah K. "Sliding Mode Observer: A Survey". International Journal of Systems Science 39.8 (2008): 751-764. Web.

[14] Plestan, F., Shtessel, Y., Brégeault, V. and Poznyak, A. (2010). "New methodologies for adaptive sliding mode control”. International Journal of Control, 83(9), pp.1907-1919.

[15] S. B.William, H. Poorya and A. B. Kartik ."Adaptive Systems: History, Techniques, Problems, and Perspectives". Systems (2014), 606-660; doi:10.3390/systems2040606.

[16] “magnetic levitation control experiments", Feedback instruments.

[17] Yadav, Shekhar, J.p.tiwari, and S.k.nagar. "Digital Control of Magnetic Levitation System using Fuzzy Logic Controller." International Journal of Computer Applications 41.21 (2012): 27-31. Web.

[18] Black, W., Haghi, P. and Ariyur, K. (2014).” Adaptive Systems: History, Techniques, Problems, and Perspectives. Systems”, 2(4), pp.606-660.

[19]Utkin, V.I., Guldner, J., and Shi, J. (1999), Sliding Mode inControl in Electromechanical Systems,London: Taylor \&Francis.

[20] Lee, H. and Utkin, V. (2007). “Chattering suppression methods in sliding mode control systems". Annual Reviews in Control, 31(2), pp.179-188.

[21] Huang, Y.J., Kuo, T.-C., and Chang, S.H. (2008), 'Adaptive Sliding-mode Control for Nonlinear Systems with Uncertain Parameters', IEEE Transactions on System, Man, and Cybernetics - Part B: Cybernetics, 38, 534-539.

[22] AL-Samarraie, S. Ahmed, and Bashar F. Midhat. "Sliding Mode Controller Design for a Crane Container". Baghdad-Iraq: IJCCCE Vol.14, No.1, 2014, 22 July 2013.

[23] Kaynak, O., Erbatur, K., and Ertugnrl M., 2001,"The Fusion of Computationally Intelligent Methodologies and Sliding-Mode Control -a Survey", IEEE Transaction on Industrial Electronics, Vol. 48, No. 1, .pp. 4-17.

[24] C. Edwards and S. Spurgeon, "Sliding Mode Control: Theory and Applications," TaylorFrancis, London, 1998.

[25] M. M. Salih,“Adaptive Sliding Mode Controllers Design with Application to Mechanical Systems.”M.Sc. Thesis, Control and 
Systems Engineering Department, University of Technology, Baghdad, Iraq, 2016.

[26] Utkin, V. I. J. Guldner, and J. Shi,” Sliding Mode Control in Electromechanical Systems", 2nd ed., Taylor and Francis, 2009.
[27] M. H. Mishary,"Sliding Mode Observer for States and Perturbation,” M.Sc. Thesis, Control and Systems Engineering Department, University of Technology, Baghdad, Iraq, 2016.

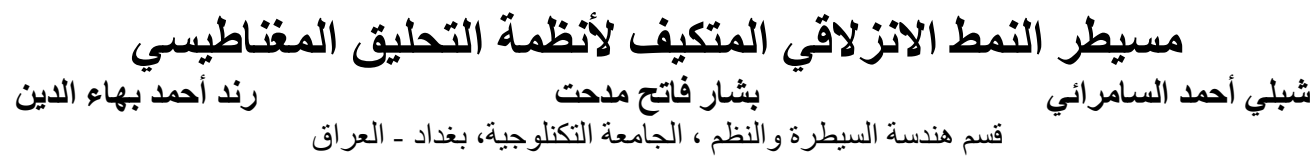

الخلاصة

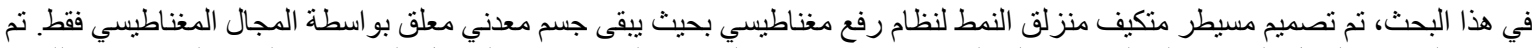

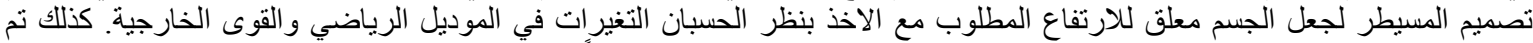

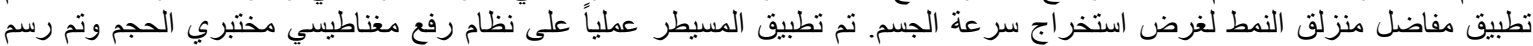
النتائج لتبيان كيفية اداء المسيطر. الكلمات الرئيسية__ مفاضل منزلق النمط، مسيطر النمط الانزلاقي المتكيف، نظام التحليق المغناطيسي.

\section{APPENDIX (A): The Maglev System Parameters and Simulink for SMD and ASMC}

Table A-1: The Maglev System Parameters.

\begin{tabular}{|cccc|}
\hline Parameters & Definition & Value & unit \\
\hline $\boldsymbol{g}$ & Gravity Acceleration & 9.81 & $\mathrm{~m} / \mathrm{s}^{2}$ \\
\hline $\boldsymbol{i}$ & Coil Current & {$[0,3]$} & $\mathrm{A}$ \\
\hline $\boldsymbol{k}$ & Coil Constant & $2.75 * 10^{-4}$ & $\mathrm{Kg}$ \\
\hline $\boldsymbol{k}_{\mathbf{1}}$ & Input Conductance & 0.397 & $1 / \Omega$ \\
\hline $\boldsymbol{L}$ & Coil Inductance & 277 & $\mathrm{mH} \mathrm{at} 1 \mathrm{KHZ}$ \\
\hline $\boldsymbol{m}$ & Mass of the Steel Ball & $20 * 10^{-3}$ & $\mathrm{~kg}$ \\
\hline $\boldsymbol{R}$ & Coil Resistance & 22 & $\Omega$ \\
\hline $\boldsymbol{u}$ & Control Voltage Signal & {$[0,5]$} & $\mathrm{v}$ \\
\hline $\boldsymbol{x}$ & Measured Position & {$[0.005,0.025]$} & $\mathrm{m}$ \\
\hline $\boldsymbol{x}_{\boldsymbol{d}}$ & Output Desired Position & {$[0.5,2.5]$} & $\mathrm{cm}$ \\
\hline
\end{tabular}

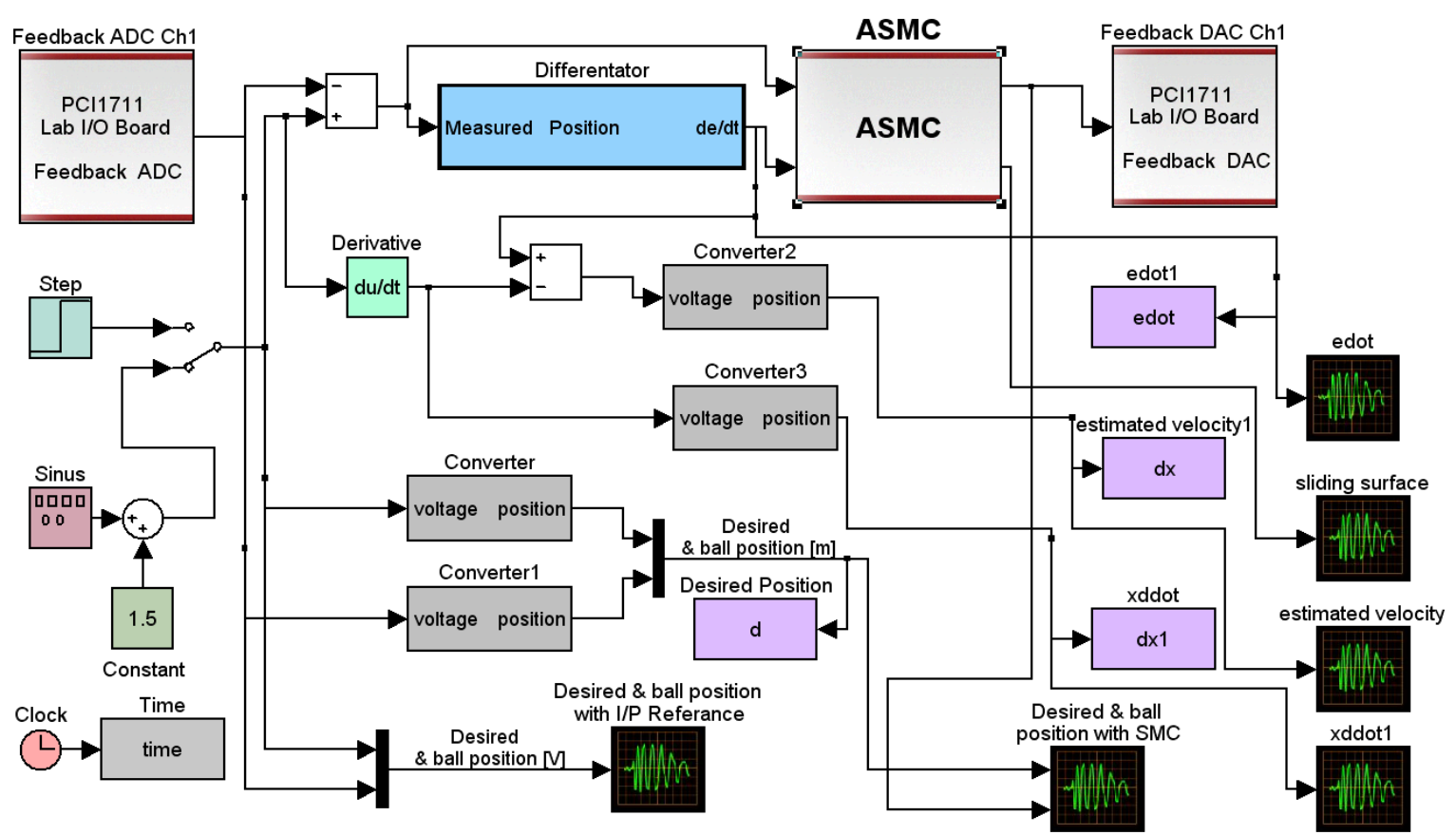

Figure A-1: The Simulink of ASMC for Maglev System (33-210 Feedback). 


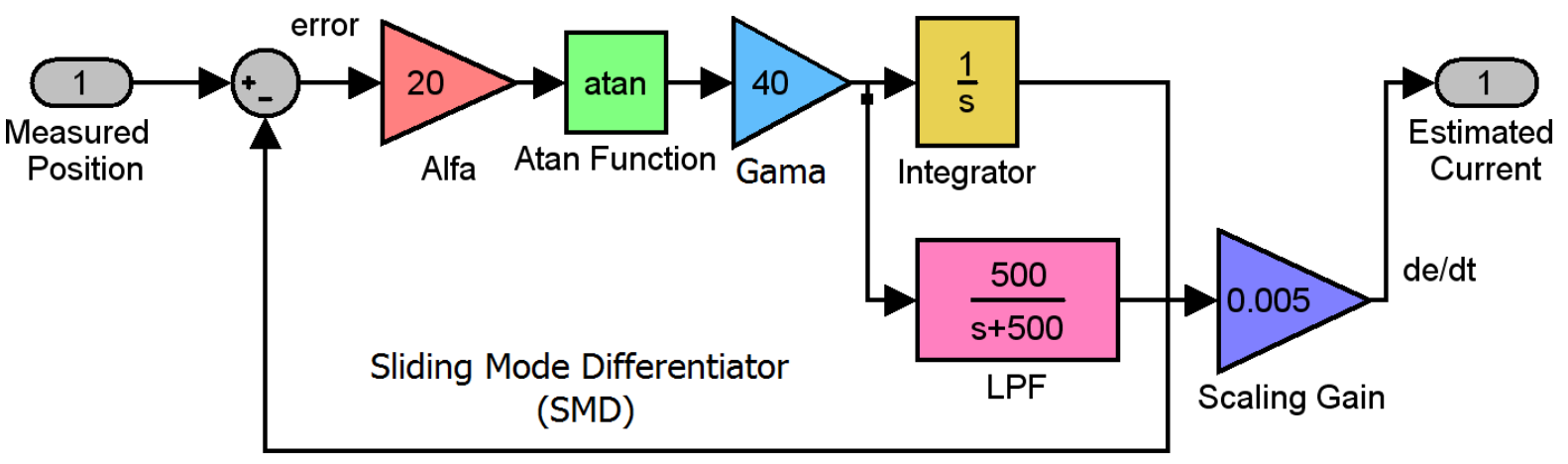

Figure A-2: The Simulink of SMD. 